\title{
Evaluation of the Effectiveness of Ophthalmology Emergency Clinic Intake Forms
}

Kaisra Esmail ${ }^{1}$, Keean Nanji ${ }^{2}$, Setareh Ziai ${ }^{1}$

${ }^{1}$ The University of Ottawa, Department of Ophthalmology ${ }^{2}$ McMaster University,

Department of Surgery,

Division of Ophthalmology

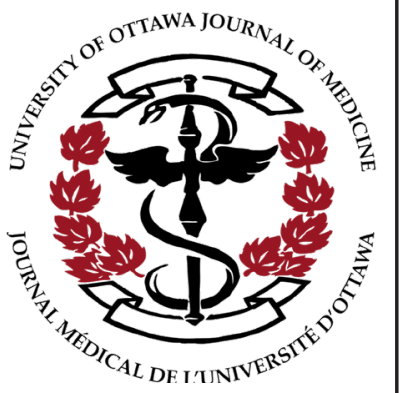

\section{ABSTRACT}

Objective: To evaluate the effectiveness of a novel patient intake form in an emergency ophthalmology clinic at a Canadian academic center. Despite the popularity of intake forms, their effectiveness has not been previously reported in the literature in an emergency ophthalmology clinic setting.

Methods: All new patients at the University of Ottawa emergency ophthalmology clinic were provided with a patient intake form to complete while waiting to be seen. Ophthalmology residents and nurses at the University of Ottawa completed an effectiveness survey evaluating the benefits of these forms after 24 months of use. Emergency ophthalmology clinics at other Canadian academic institutions were questioned regarding their use of patient intake forms.

Results: Nine residents and two nurses completed the effectiveness survey. The mean (SD) score assessing the use of the form ( $1=$ never, $5=$ every patient encounter) was $3.90(1.20)$. The greatest perceived benefit involved improved clinic efficiency (91\%). Responses from $100 \%$ of participants indicated that the form should continue to be used in practice. Of the other 14 ophthalmology residency programs in Canada, nine currently do not use an intake form, two have forms completed by nurses and three utilize a form but are dissatisfied with their results.

Conclusions: Our results suggest that there are benefits with respect to clinic efficiency when utilizing patient intake forms in an emergency ophthalmology setting. The use of similar forms may provide an opportunity to improve clinical practice at other academic institutions within Canada.

\section{RÉSUMÉ}

Objectif: Évaluer l'efficacité d'un nouveau formulaire d'admission des patients dans une clinique ophtalmologique d'urgence au sein d'un centre universitaire canadien. Malgré la popularité des formulaires d'admission, leur efficacité n'a pas encore été rapportée dans la littérature dans un contexte de clinique ophtalmologique d'urgence. Méthodologie: Tous les nouveaux patients de la clinique ophtalmologique d'urgence de l'Université d'Ottawa ont reçu un formulaire d'admission à remplir en attendant d'être examinés. Les résidents et les infirmières en ophtalmologie de I'Université d'Ottawa ont répondu à un questionnaire d'efficacité évaluant les avantages de ces formulaires après 24 mois d'utilisation. Les cliniques ophtalmologiques d'urgence d'autres institutions universitaires canadiennes ont été interrogées sur leur utilisation des formulaires d'admission des patients.

Résultats: Neuf résidents et deux infirmières ont répondu au questionnaire d'efficacité. Le score moyen (SD) évaluant l'utilisation du formulaire (1=jamais, $5=$ chaque rencontre avec le patient) était de 3,90 (1,20). Le plus grand avantage perçu concernait l'amélioration de l'efficacité de la clinique (91\%). Les réponses de $100 \%$ des participants ont indiqué que le formulaire devrait continuer à être utilisé en pratique. Sur les 14 autres programmes de résidence en ophtalmologie au Canada, neuf n'utilisent pas actuellement de formulaire d'admission, deux ont des formulaires remplis par des infirmières et trois utilisent un formulaire mais sont insatisfaits de leurs résultats. Conclusions: Nos résultats suggèrent qu'il y a des avantages en termes d'efficacité clinique à utiliser des formulaires d'admission des patients dans un environnement ophtalmologique d'urgence. Ainsi, l'utilisation de formulaires similaires pourrait permettre d'améliorer la pratique clinique dans d'autres établissements universitaires au Canada.

Keywords: Patient intake forms; Ophthalmology; Emergency clinic; Collaboration; Patient satisfaction 


\section{INTRODUCTION}

A patient's interaction with the healthcare system is a complicated and often stressful process. Eliciting an accurate medical history is an essential part of a physicianpatient encounter, particularly in the emergency setting. There are however, multiple barriers to reliable history taking, including but not limited to: respondents providing inaccurate reports out of fear of embarrassment (1), potential physician cultural, race or gender biases resulting in a variability of questions (2), and physicians interrupting patients and/or using medical jargon that could lead to incomplete problem presentation and a partial history (3). Additionally, patients do not always remember their complete past medical and medication history, and thus it is often challenging to accurately produce this information on command. Patient intake forms provide patients with the opportunity to answer these questions on their own in a low-pressure environment, while awaiting their physician encounter, and therefore have the potential to reduce these barriers.

Patient intake forms are templates that facilitate a more accurate and efficient method of gathering important information. They are traditionally completed by patients while in the waiting room and include relevant information for a healthcare provider to properly assess and treat a patient. Intake forms frequently include information such as a patient's history of presenting illness, past medical history, and current medications. They are intended to reduce the amount of time spent gathering information during the clinical encounter, allowing physicians to focus on explaining information and clarifying patient concerns. These forms also provide patients with the opportunity to confirm information by communicating with family members or other healthcare professionals before the clinical encounter.

Additionally, patient intake forms have the potential to affect patient satisfaction, an important marker in any healthcare system. In addition to gratifying patients, satisfied patients are more likely to have improved compliance (4) and have an increased likelihood for improvement in health related quality of life (5). From a healthcare provider standpoint, increased patient satisfaction has been associated with fewer complaints from patients (6), and has been shown to be linked to staff satisfaction. A qualitative review examining 20 years of patient satisfaction literature highlighted that patients evaluate their experience based on a combination of the medical treatment received and the way in which they are treated (7). A patient's experience begins well before their first interaction with a healthcare professional, thus optimizing their experience in the waiting room is of utmost importance.

A study investigating patient satisfaction in an ophthalmology clinic found that patient satisfaction with wait time was the strongest driver of overall satisfaction score (8). Interestingly, the literature has shown that patients' perceived waiting time rather than actual waiting time has been more strongly correlated with patient satisfaction $(9,10)$. The issue of time also plays a role in the information dispensation phase of the clinical encounter. Patients have described that perceiving to be under a time constraint as well as feeling rushed are barriers to clarifying the concerns that they have (11). Similarly, physicians have cited time constraints as a significant obstacle to their ability to act in an evidence-based manner $(12,13)$. In an ophthalmology clinic, it has been demonstrated that significantly more time is spent on conversing between the ophthalmologist and patient than on any other activity during the clinical encounter (14). A major portion of these conversations are spent gathering pertinent medical information from patients in order to establish a diagnosis. Patient intake forms have often been suggested as a solution to improve efficiency in a clinical setting. Consequently, the purpose of this investigation was to introduce a novel patient intake form at the University of Ottawa Eye Institute's emergency clinic and assess its utility and effectiveness.

\section{METHODS}

\section{Evaluation of Patient Intake Forms at the University of Ottawa}

Ethics approval was waived due to the quality improvement nature of this study. Ophthalmology specific patient intake forms were created and introduced by a resident and attending physician at the University of Ottawa Eye Institute's emergency eye clinic. Once patients had registered at the front desk, they were provided with a patient intake form to complete [Appendix] while waiting to be seen. The intake form was provided in English and French and consisted of questions pertaining to other healthcare practitioners in the patient's circle of care, the patient's past ocular and medical histories, current medications, family history, as well as relevant questions regarding the 
patient's social history. After 24 months of consistent use of the form, a survey [Appendix] was developed in order to determine its efficacy. All residents and nurses who work at the emergency clinic were provided with an anonymous electronic version of the survey. The survey consisted of six questions and was focused on how frequently the individual used the form, whether they found it helpful, and which aspects were the most beneficial.

\section{Patient Intake Forms at Other Canadian Universities}

Residents in emergency ophthalmology clinics at the other 14 Canadian universities with ophthalmology residency programs were surveyed in order to determine their use of a patient intake form. Programs that indicated the use of a form were further asked about the role of the individual completing the form (e.g. patients vs nurses vs physicians), and to comment on its usefulness.

Figure 1: Graphical representation on the role of individuals who completed the effectiveness survey.

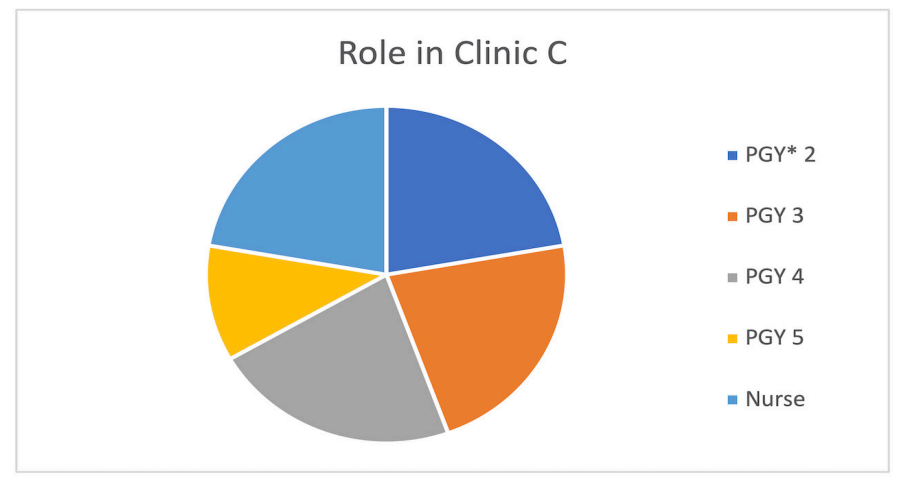

PGY $=$ postgraduate year

\section{RESULTS}

\section{Survey Completion}

At the University of Ottawa Eye Institute, the emergency eye clinic is primarily staffed by the ophthalmology residents and two nurses. There are 12 ophthalmology residents from Post Graduate Years (PGY) 2-5, excluding the author. Nine of the 12 residents completed the effectiveness survey. The two nurses who predominantly staff the emergency clinic also responded to the survey (Figure 1).

\section{Utilization of Information}

As part of the effectiveness survey, individuals were asked if they utilized the information from the patient intake form when seeing new consults (yes/no) and if so, how often
( $1=$ never, 5 = every patient encounter). Nine individuals indicated that they utilized the form when seeing new consults. Ten individuals indicated how often they use the form. The mean (SD) score provided with regards to frequency of use was 3.90 (1.20) (Figure 2).

Figure 2: Graphical representation of the frequency of information use.

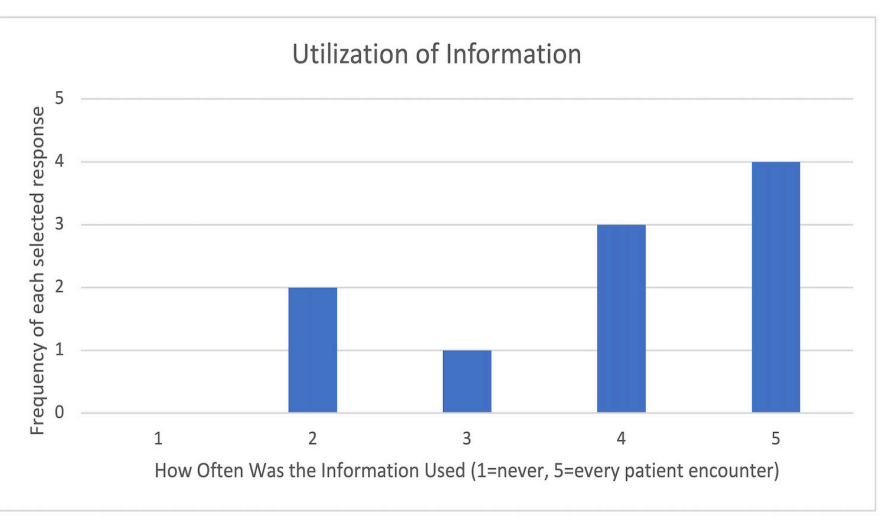

\section{Benefits of the Intake Form}

The next section of the effectiveness survey evaluated the benefits of implementing patient intake forms. Individuals were asked to rate how helpful they found the form (1 = not at all, $5=$ very helpful) and were subsequently asked what they thought the most beneficial aspect was. They were instructed to select as many options as they felt were appropriate (or none) from a list consisting of: improved clinic efficiency, improved accuracy of medical history, quick access to names of family physician/optometrist/ ophthalmologist, or keeping patients occupied while waiting for their appointment. Individuals were also provided with a designated area to indicate any other benefits that they experienced.

All 11 individuals rated how helpful they found the form and indicated what they perceived to be the greatest benefits. The mean (SD) value with regards to perceived helpfulness was 4.0 (1.0). The greatest perceived benefit was improved clinic efficiency (91\%) and the least indicated benefit was improved accuracy of medical history (45\%) (Table 1).

Table 1: Frequency of the Perceived Benefits of the Intake Form ( $n=11)$.

\begin{tabular}{|c|c|}
\hline Beneficial Aspect of the Form & $\begin{array}{c}\text { Individuals Who Noted } \\
\text { This Benefit (\%) }\end{array}$ \\
\hline Improved clinic efficiency & $10 / 11(91)$ \\
\hline Improved accuracy of medical history & $5 / 11(45)$ \\
\hline $\begin{array}{c}\text { Quick access to names of other HCPs to } \\
\text { alloow for collaboration/communication }\end{array}$ & $6 / 11(55)$ \\
\hline $\begin{array}{c}\text { Keeping patients occupied while waiting } \\
\text { for their appointment }\end{array}$ & $7 / 11(64)$ \\
\hline
\end{tabular}




\section{Continuation of the Intake Form}

The final question of the effectiveness survey asked individuals whether or not they believe that the form should continue to be used. All 11 individuals responded that in their opinion, the form should continue to be used in clinical practice.

\section{Patient Intake Forms at Other Institutions}

A representative from each of the 14 other ophthalmology residency programs in Canada provided information regarding whether they currently use a patient intake form in their emergency clinic. The majority of clinics (9 out of 14; $64 \%$ ) currently do not utilize a patient intake form. Of the five schools that do, two have nurses complete the form (Table 2). Each of the three clinics that have patients complete the intake form reported some degree of dissatisfaction with their current results. One clinic indicated that they find the form to be redundant as the residents ask patients the same questions. Another indicated that the form is not used consistently by the residents working at their clinic. Rather, it is used variably depending on resident preference. The last clinic indicated that they did not find the form to be very helpful but did not elaborate as to why they felt this way.

Table 2: Current Status of Patient Intake Form Use at Other Canadian Ophthalmology Institutions.

\begin{tabular}{|c|c|}
\hline Current Status of Form Use & Frequency (\%) \\
\hline No form is currently in use & $9 / 14(64)$ \\
\hline $\begin{array}{c}\text { A form is currently used and is completed } \\
\text { by patients }\end{array}$ & $3 / 14(21)$ \\
\hline $\begin{array}{c}\text { A form is currently used and is completed } \\
\text { by nurse }\end{array}$ & $2 / 14(14)$ \\
\hline
\end{tabular}

\section{DISCUSSION}

The results of this investigation suggest that information gathered from patient intake forms is frequently utilized by healthcare professionals and have many benefits when implemented in an emergency ophthalmology clinic. The most experienced benefit was a subjective improvement in clinic efficiency. Other benefits include improved accuracy of medical information, quick access to contact information of other healthcare professionals for collaborative care, and keeping patients occupied in the waiting room. Most of the other Canadian academic institutions do not have a similar form in place in their emergency eye clinic, and those that do may not be experiencing the same benefits. Lack of consistent use of the form as well as poorly designed questions are two potential reasons as to why other institutions were not experiencing similar benefits. As a result, we believe that introducing a form such as ours at other Canadian academic institutions presents an opportunity for improved patient and healthcare provider experiences across the country.

The current literature reports similar findings as ours when utilizing patient intake forms. They have consistently been shown to be a reliable and valid method of collecting patient information (15-17). Consequently, clinicians are able to gather high-quality information in an efficient lowresource intensive manner. Patient chart data has been shown to be more complete when patients are provided with a self-administered health history questionnaire prior to the encounter, and this has resulted in physicians being able to recognize more health problems in a given encounter (18). This is particularly important in an emergency clinic setting when healthcare providers have little to no background information on the patient prior to the encounter. Additionally, patient intake forms provide patients with a task to complete while waiting. When occupied, patient satisfaction ratings have been reported to increase despite no changes to their wait time (19). Greater patient satisfaction has been linked to improved patient compliance with medical advice (4). This is important in any healthcare setting but particularly in an emergency clinic setting when there is often no scheduled follow up.

There are, however, several limitations that must be considered when examining the results of this investigation. First, much of our data is subjective in nature. There undoubtedly is great merit to subjective data, however, having both subjective and objective measures of a particular variable would provide more information regarding the benefits of our intervention. For instance, when examining clinic efficiency, comparing the time spent by healthcare professionals eliciting a history from a patient before and after the intake forms were implemented would have augmented our capacity to evaluate their effect on efficiency. Additionally, as this was a single site investigation, there was a relatively small sample who completed the effectiveness survey. A larger sample size would have given us greater power to detect the effect of our intervention. Lastly, patients were not surveyed regarding how long the intake form took them to complete or regarding their opinion of the forms. As a result, despite the current literature outlining the benefits regarding perceived wait time and patient satisfaction, 
we cannot be certain that these benefits translate to our investigation.

In order to address these limitations, we suggest that future investigations involve more healthcare professionals to increase the sample size of the effectiveness survey. Furthermore, it would be beneficial to track objective measures of the variables that we investigated such as patient wait times, time spent by healthcare professionals eliciting a patient history, and patient chart completeness to supplement the subjective benefits of the patient intake forms. We would also suggest that an additional patient survey be completed by those involved to provide another perspective evaluating the benefits of the form. Future directions may include collaborating with other institutions to implement the same form in their emergency ophthalmology clinic and performing a comparative analysis.

\section{CONCLUSION}

In summation, the current literature has well documented the benefits of utilizing intake forms in general clinical practice. Our investigation examined the effects of patient intake forms in a unique setting - an emergency ophthalmology clinic. Our results suggest that there are benefits with respect to efficiency in clinic when utilizing these forms. Furthermore, our investigation details a great opportunity for other Canadian ophthalmic institutions to implement such a form. They are a simple addition to clinical practice and offer numerous benefits to both healthcare professionals and patients.

\section{REFERENCES}

1. Redelmeier DA, Tu J V, Schull MJ, Ferris LE, Hux JE Problems for clinical judgement: 2. Obtaining a reliable past medical history. CMAJ 2001 Mar; 164(6): 809-13.

2. James TL, Feldman J, Mehta SD. Physician Variability in History Taking When Evaluating Patients Presenting with Chest Pain in the Emergency Department. Acad Emerg Med 2006 Jan; 13(2): 147-52.

3. Koch-Weser S, Dejong W, Rudd RE. Medical word use in clinical encounters. Heal Expect 2009; 12(4): 371-82.

4. Miaoulis G, Gutman J, Snow MM. Closing the Gap: The Patient-Physician Disconnect. Health Mark Q 2009 Dec; 26(1): 56-68.

5. Renzi C, Tabolli S, Picardi A, Abeni D, Puddu P, Braga M. Effects of patient satisfaction with care on health-related quality of life: a prospective study. J Eur Acad Dermatology Venereol 2005 Nov; 19(6): 712-8.

6. Stelfox HT, Gandhi TK, Orav EJ, Gustafson ML. The relation of patient satisfaction with complaints against physicians and malpractice lawsuits. Am J Med 2005 Oct; 118(10): 1126-33.

7. Press I. Patient Satisfaction: Defining, Measuring, and
Improving the Experience of Care. J Healthcare Qual. 2003 May; 25(3):47

8. Welch SJ. Twenty Years of Patient Satisfaction Research Applied to the Emergency Department: A Qualitative Review. Am J Med Qual 2010 Jan; 25(1): 64-72.

9. McMullen M, Netland PA. Wait time as a driver of overall patient satisfaction in an ophthalmology clinic. Clin Ophthalmol 2013 Aug; 7: 1655-60.

10. Bursch B, Beezy J, Shaw R. Emergency department satisfaction: what matters most? Ann Emerg Med 1993 Mar; 22(3): 586-91.

11. Thompson DA, Yarnold PR, Williams DR, Adams SL. Effects of actual waiting time, perceived waiting time, information delivery, and expressive quality on patient satisfaction in the emergency department. Ann Emerg Med 1996 Dec; 28(6): 657-65.

12. Wolff LS, Massett HA, Weber D, Mockenhaupt RE, Hassmiller S, Maibach EW. Opportunities and barriers to disease prevention counseling in the primary care setting: a multisite qualitative study with US health consumers. Health Promot Int 2010 Sep; 25(3): 265-76.

13. Presseau J, Sniehotta FF, Francis JJ, Campbell NC. Multiple goals and time constraints: perceived impact on physicians' performance of evidence-based behaviours. Implement Sci 2009 Nov; 4: 77.

14. McColl A, Smith H, White P, Field J. General practitioner's perceptions of the route to evidence based medicine: a questionnaire survey. BMJ 1998 Jan; 316(7128): 361-5.

15. Read-Brown S, Hribar MR, Reznick LG, et al. Time Requirements for Electronic Health Record Use in an Academic Ophthalmology Center. JAMA Ophthalmol 2017 Nov; 135(11): 1250.

16. Gilkison CR, Fenton M V., Lester JW. Getting the Story Straight: Evaluating the Test-Retest Reliability of a University Health History Questionnaire. J Am Coll Heal 1992 May; 40(6): 247-52

17. Pecoraro RE, Inui TS, Chen MS, Plorde DK, Heller JL. Validity and reliability of a self-administered health history questionnaire. Public Health Rep 1979 Jun; 94(3): 231-8.

18. Puhan MA, Ahuja A, Van Natta ML, Ackatz LE, Meinert C Studies of Ocular Complications of AIDS Research Group. Interviewer versus self-administered health-related quality of life questionnaires - does it matter? Health Qual Life Outcomes 2011 May; 9: 30.

19. Inui TS, Jared RA, Carter WB, et al. Effects of a selfadministered health history on new-patient visits in a general medical clinic. Med Care 1979 Dec; 17(12): 1221-8.

20. Dansky KH, Miles J. Patient satisfaction with ambulatory healthcare services: waiting time and filling time. Hosp Health Serv Adm 1997 Jul; 42(2): 165-77. 